\title{
$\beta$-Catenin/TCF4 Complex-Mediated Induction of the NRF3 (NFE2L3) Gene in Cancer Cells
}

\author{
Shiori Aono ${ }^{1,+}$, Ayari Hatanaka ${ }^{1,+}$, Atsushi Hatanaka ${ }^{1,2}$, Yue Gao ${ }^{1}$, Yoshitaka Hippo ${ }^{3}{ }^{\mathbb{D}}$, \\ Makoto Mark Taketo ${ }^{4}$, Tsuyoshi Waku ${ }^{5}$ and Akira Kobayashi ${ }^{6, *(D)}$ \\ 1 Laboratory for Genetic Code, Graduate School of Life and Medical Sciences, Doshisha University, \\ Kyotanabe, Kyoto 610-0394, Japan \\ 2 Japan Society for the Promotion of Science, Tokyo 102-0083, Japan \\ 3 Division of Molecular Carcinogenesis, Chiba Cancer Center Research Institute, Chiba, Chiba 260-8717, Japan \\ 4 Division of Experimental Therapeutics, Graduate School of Medicine, Kyoto University, \\ Kyoto 606-8501, Japan \\ 5 Laboratory for Genetic Code, Department of Life and Medical Sciences, Faculty of Life and Medical Sciences, \\ Doshisha University, Kyotanabe, Kyoto 610-0394, Japan \\ 6 Laboratory for Genetic Code, Graduate School of Life and Medical Sciences, and Department of Life and \\ Medical Sciences, Faculty of Life and Medical Sciences, Doshisha University, Kyotanabe, \\ Kyoto 610-0394, Japan \\ * Correspondence: akobayas@mail.doshisha.ac.jp; Tel.: +81-774-65-6273 \\ + These authors contribute equally to this work.
}

Received: 14 April 2019; Accepted: 3 July 2019; Published: 8 July 2019

\begin{abstract}
Remarkable upregulation of the NRF2 (NFE2L2)-related transcription factor NRF3 (NFE2L3) in several cancer tissues and its correlation with poor prognosis strongly suggest the physiological function of NRF3 in tumors. Indeed, we had recently uncovered the function of NRF3, which promotes cancer cell proliferation by p53 degradation via the $20 \mathrm{~S}$ proteasome. Nevertheless, the molecular mechanism underlying the induction of NRF3 gene expression in cancer cells is highly elusive. We herein describe that NRF3 upregulation is induced by the $\beta$-catenin/TCF4 complex in colon cancer cells. We first confirmed high NRF3 mRNA expression in human colon cancer specimens. The genome database indicated that the human NRF3 gene possesses a species-conserved WRE sequence (TCF/LEF consensus element), implying that the $\beta$-catenin/TCF complex activates NRF3 expression in colon cancer. Consistently, we observed that the $\beta$-catenin/TCF4 complex mediates NRF3 expression by binding directly to the WRE site. Furthermore, inducing NRF3 activates cell proliferation and the expression of the glucose transporter GLUT1. The existence of the $\beta$-catenin/TCF4-NRF3 axis was also validated in the intestine and organoids of $A p c$-deficient mice. Finally, the positive correlation between NRF3 and $\beta$-catenin target gene expression strongly supports our conclusion. Our findings clearly demonstrate that NRF3 induction in cancer cells is controlled by the $\mathrm{Wnt} / \beta$-catenin pathway.
\end{abstract}

Keywords: NRF3; NRF2; $\beta$-catenin; Wnt signaling; GLUT1; transcription; colorectal cancer; organoid

\section{Introduction}

The development of human cancer genome databases such as The Cancer Genome Atlas (TCGA) and Oncomine have led directly to the discovery of significant functional mutations in genes and pathways [1,2]. This information also indicates that the biological roles and regulatory mechanisms of numerous genes in tumorigenesis are not defined. Thus, determining these unknown roles will be indispensable for the development of promising targeted molecules for new cancer therapies and precision medicine. 
In this regard, we focused on the transcription factor NRF3 (NFE2L3), because it is highly expressed in several cancers, including colorectal adenocarcinoma, and is correlated with poor prognosis [3]. NRF3, which was originally discovered by our group [4], belongs to the cap " $\mathrm{N}$ " collar (CNC) family of six transcription factors, including NRF2 (NFE2L2) and NRF1 (NFE2L1); NRF2 is a famous cancer driver gene and an oxidative stress response transcription factor, and NRF1 sustains proteostasis by mediating proteasome gene expression [5-7]. The physiological function of NRF3 remains unknown; Nrf3 knockout mice do not show obvious abnormalities [8-10]. Recently, we found that NRF3 promotes the proliferation of cancer cells by degrading the tumor suppressor $\mathrm{p} 53$ through $20 \mathrm{~S}$ proteasome activation [11] (manuscript submitted by Waku et al.). In support of our findings, accumulating evidence indicates that NRF3 regulates the growth and metastasis of thyroid, pancreatic, testis and breast cancer [12-16]. Nevertheless, the molecular mechanism underlying NRF3 gene induction in cancer cells is poorly understood.

A large body of evidence has revealed that the accumulation of multiple gene mutations underlies the development of cancer [17]. For instance, the Wnt/ $\beta$-catenin pathway, which is essential for normal intestinal growth and development, plays a key role in the initiation of colorectal cancer progression [18-20]. Inactivation of the adenomatous polyposis coli (APC) gene and the CTNNB1 gene encoding $\beta$-catenin is an initial event leading to the development of adenoma in most sporadic cases. These genetic alterations stabilize the $\beta$-catenin protein and promote its nuclear entry, leading to the activation of gene expression by T-cell factor/lymphoid enhancer-binding factor (TCF/LEF) family proteins binding to the WRE sequence (Wnt response element, TCF/LEF consensus element). The TCF/LEF family consists of TCF1, TCF3, TCF4 and LEF1. The upregulation of $\beta$-catenin/TCF target genes, such as $c-M Y C, A X I N 2$ and LGR5, regulates cell proliferation and stemness in epithelial stem and progenitor cells [21-23]. Thus, constitutive activation of $\beta$-catenin by APC mutations gives rise to hyperplastic epithelium. Further carcinoma development requires an activating mutation in the $\mathrm{K}$-ras gene and loss of the $p 53$ gene.

Gene alterations dramatically change the metabolic status of cancer cells $[21,24,25]$. One type of metabolic reprogramming in cancer cells is the Warburg effect, which is characterized by a shift toward glycolysis from oxidative phosphorylation. Indeed, certain cancer cells upregulate the gene expression of the glucose transporters GLUT1 (SLC2A1) and GLUT3 (SLC2A3) to increase glucose uptake, which correlates with poor prognosis.

We herein report that the molecular mechanisms of NRF3 induction in cancer cells involve the $\beta$-catenin/TCF4 complex. We first identified a species-conserved WRE site that is recognized by the $\beta$-catenin/TCF4 complex in the NRF3 gene. The $\beta$-catenin/TCF4 complex mediates NRF3 expression in several cancer cells through binding to its WRE site. We also found that upregulating NRF3 augments cell proliferation and the expression of the GLUT1 gene. The biological significance of the $\beta$-catenin/Tcf4-Nrf3 axis was confirmed by deletion of the Apc gene in the mouse intestine and its derived organoids. Finally, we found a positive correlation between NRF3 and c-MYC or LGR5, target genes of the $\beta$-catenin/TCF4 complex. Altogether, this study reveals the $\beta$-catenin/TCF4-NRF3 axis as the molecular basis for NRF3 gene upregulation in cancer cells.

\section{Results}

\subsection{High Expression of The NRF3 Gene in Human Colorectal Cancer Specimens}

To further examine the biological relevance of NRF3 in cancer, we first conducted an NRF3 expression analysis using a human cancer RNA dot blot (Figure 1). The blot possesses RNA derived from both tumor $(\mathrm{T})$ and adjacent normal $(\mathrm{N})$ tissues for various human cancers. Intriguingly, NRF3 mRNA expression was induced in several types of cancer, especially in colon and rectal carcinoma. These results strengthen our hypothesis that NRF3 is involved in colorectal carcinogenesis. 
A

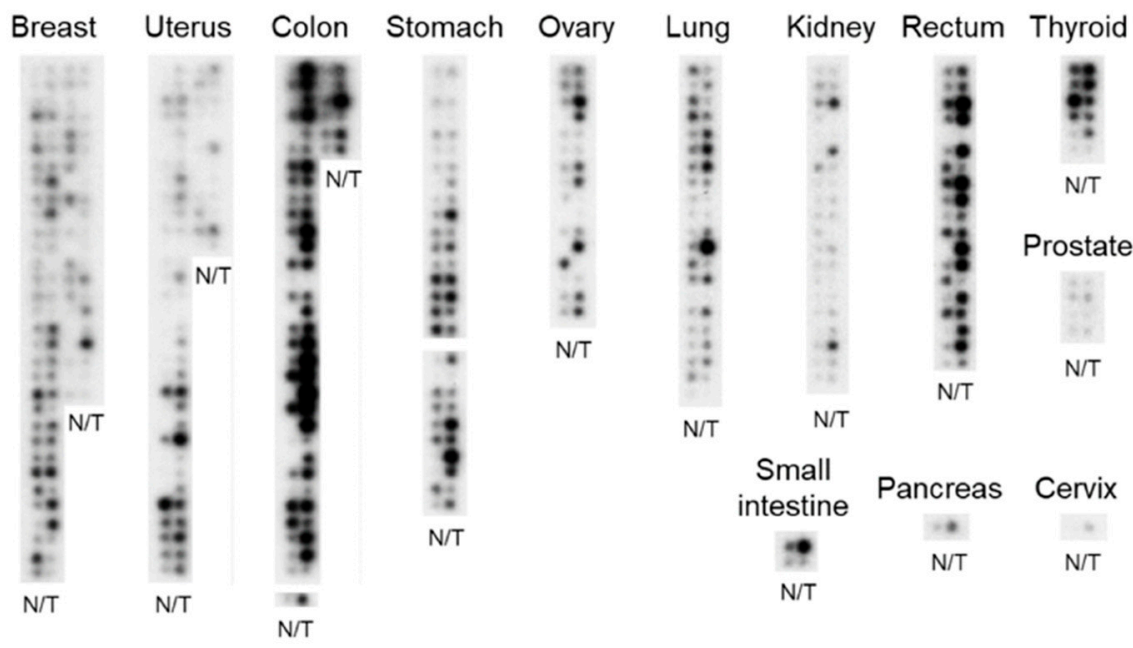

B

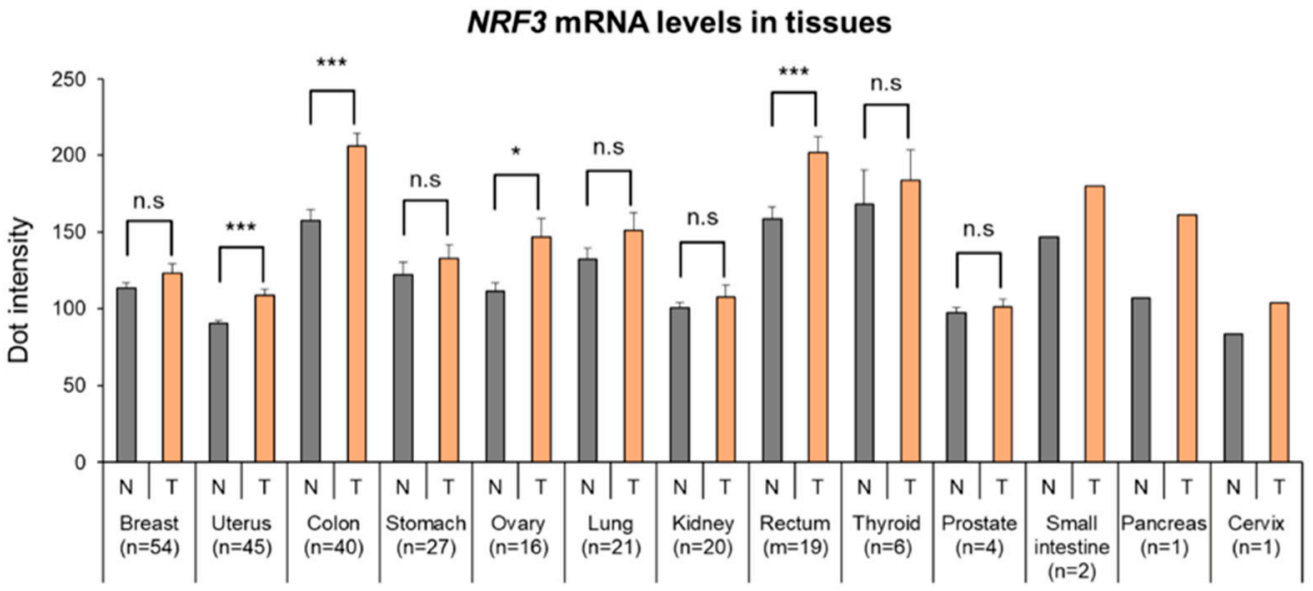

Figure 1. High induction of NRF3 gene expression in human tumor tissues. (A) RNA dot blot analysis of NRF3 using the Human Multiple Tissue Expression (MTE ${ }^{\mathrm{TM}}$ ) Array. This array contains dots of polyA ${ }^{+}$RNA from 76 different human tissues, normalized to ubiquitin mRNA levels. T; tumor tissue, $\mathrm{N}$; adjacent normal tissue. (B) The bar graph shows the quantified signal intensity of each dot. The data are presented as the mean \pm SD. $n$, patient number. ${ }^{*} p<0.05,{ }^{* * *} p<0.005$ (t-test). n.s., not significant.

\subsection{The $\beta$-catenin/TCF4 Complex Directly Mediates NRF3 Gene Induction in Cancer Cells}

To investigate the molecular mechanism underlying NRF3 gene induction in colorectal cancer cells, we considered possible regulation by the $\beta$-catenin/TCF complex. Mutations in the Wnt- $\beta$-catenin pathway are crucial initial events in colon carcinogenesis [18-20]. We searched the regulatory region of the NRF3 gene and successfully found a species-conserved WRE sequence as the TCF recognition element in its first intron (Figure 2A). 
A

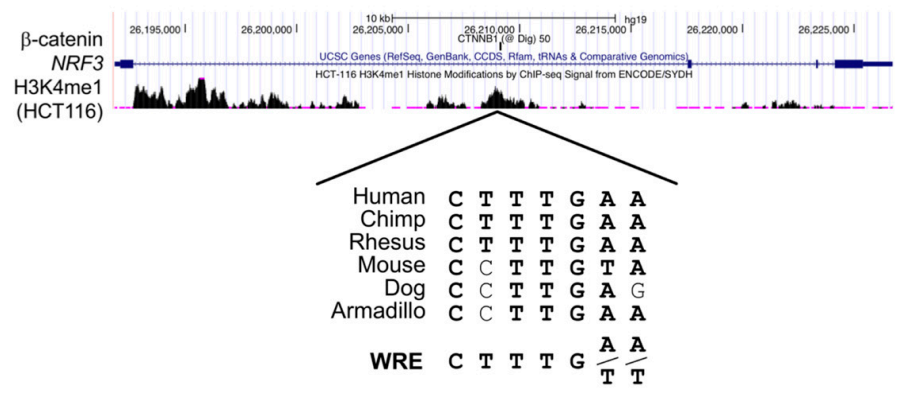

B

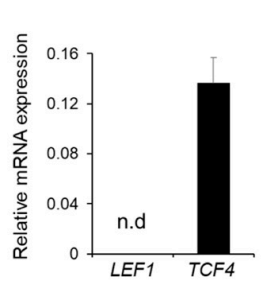

C

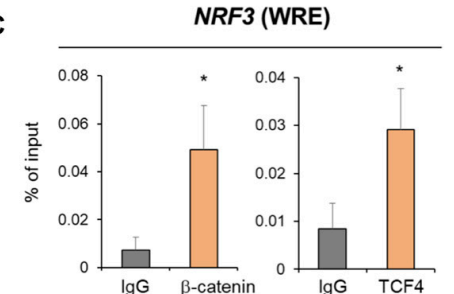

H

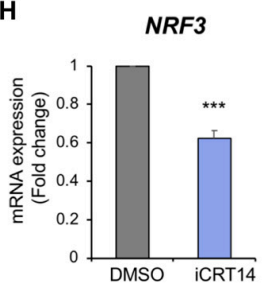

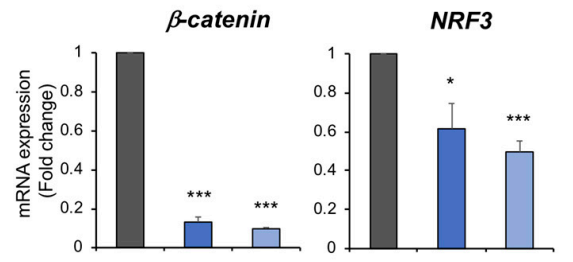

F

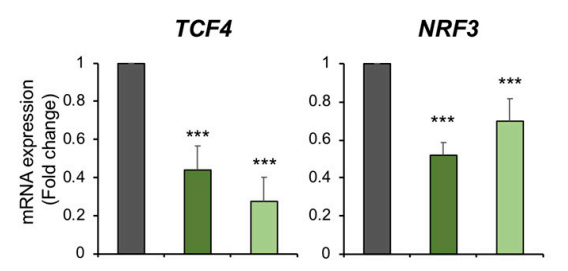

E
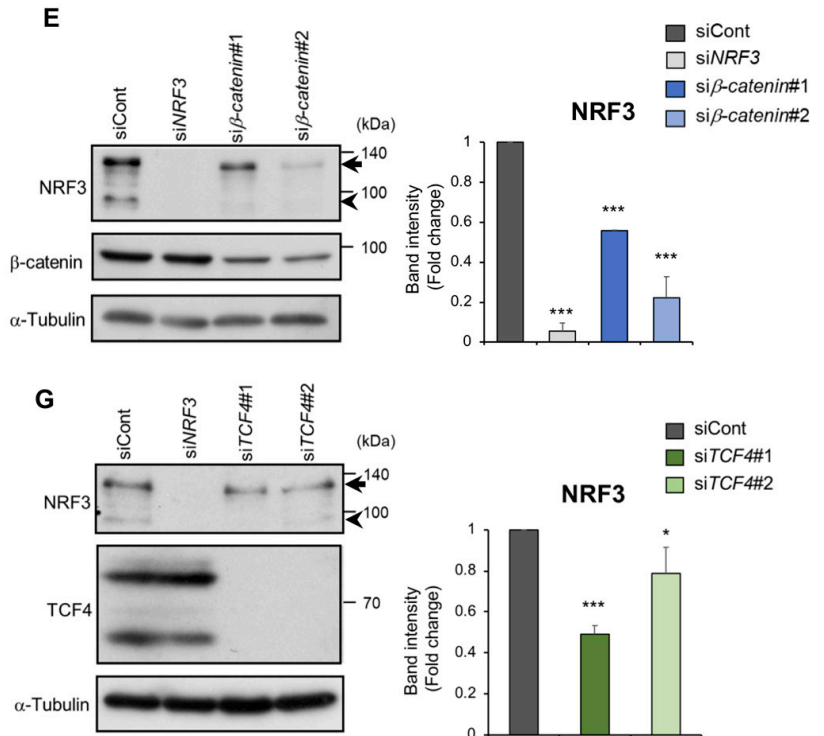

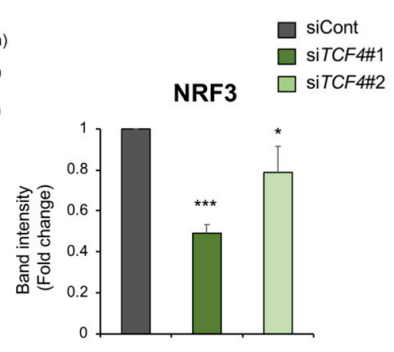

Figure 2. The $\beta$-catenin/TCF4 complex induces NRF3 gene expression in colon cancer cells. (A) Species conservation of the WRE site (TCF/LEF consensus element) in the NRF3 gene. ChIP peaks of $\beta$-catenin and histone H3K4me1 (a marker of a transcriptionally active locus) are shown from the UCSC Genome Browser data from ChIP-seq analyses of digestive tract-derived cells. (B) qRT-PCR shows the dominant expression of TCF4 rather than LEF1 in HCT116 cells. n.d., not detectable. (C) ChIP analysis using HCT116 cells indicated the binding of $\beta$-catenin and TCF4 to the WRE sequence in the NRF3 gene. (D-G) Knockdown of $\beta$-catenin (D, E) or TCF4 (F, G) significantly reduced NRF3 expression at both the mRNA $(\mathbf{D}, \mathbf{F})$ and protein levels $(\mathbf{E}, \mathbf{G})$. Two independent siRNAs against the indicated genes were transfected into HCT116 cells, and qRT-PCR and western blot analyses were performed $48 \mathrm{~h}$ after transfection. The arrows and arrowheads in the immunoblots indicate the cytoplasmic and nuclear forms of NRF3, respectively. An immunoblot using an anti-TCF4 antibody showed two splicing variants of the TCF4 protein (G). (H) The $\beta$-catenin/TCF4 complex inhibitor iCRT14 also suppressed NRF3 mRNA expression in HCT116 cells. mRNA and protein expression were normalized to $\beta$-actin mRNA and $\alpha$-Tubulin protein expression, respectively. The data are presented as the mean $\pm \operatorname{SD}(n=3)$. ${ }^{*} p<0.05,{ }^{* * *} p<0.005$ ( $t$-test in $\mathrm{C}$ and $\mathrm{H}$, ANOVA/Tukey in $\mathbf{D}-\mathbf{G}$ ). 
To further confirm our hypothesis, we explored whether $\beta$-catenin/TCF binds directly to the WRE sequence in the NRF3 gene. In the TCF/LEF family, TCF4 was reported to be abundantly expressed in colon cancer cells [19,26]. Supporting this notion, we observed that TCF4 mRNA levels were much higher than LEF1 mRNA levels in HCT116 cells (Figure 2B), implying that TCF4 could be a regulator of NRF3 gene expression. We next carried out a chromatin immunoprecipitation analysis to assess the direct binding of both $\beta$-catenin and TCF4 to the WRE sequence (Figure $2 \mathrm{C}$ ). As expected, the data clearly demonstrated the recruitment of $\beta$-catenin/TCF4 to the NRF3 gene.

We addressed the question of whether the $\beta$-catenin/TCF4 complex mediates NRF3 expression (Figure 2D-G). For this purpose, we used two different approaches. First, we examined the effects of $\beta$-catenin or TCF4 knockdown on NRF3 expression in HCT116 cells. siRNAs against these two genes significantly reduced NRF3 expression at both the mRNA and protein levels. Next, we chemically inhibited the $\beta$-catenin/TCF4 complex with iCRT14, which attenuates its DNA binding activity [27] (Figure 2H). As expected, iCRT14 treatment substantially reduced NRF3 mRNA levels. Collectively, these results strongly indicate that the $\beta$-catenin/TCF4 complex is a direct regulator of NRF3 gene induction in colon cancer cells.

\subsection{The $\beta$-catenin/TCF4-NRF3 Axis Is Conserved in Other Cancer Cells}

We also investigated $\beta$-catenin/TCF4-mediated NRF3 regulation in other human cancer cell lines: DLD-1 (colorectal adenocarcinoma), H1299 (non-small cell lung carcinoma), A172 (glioblastoma) and HeLa (cervical epithelioid carcinoma) (Figure 3A). All these cell lines, except for HeLa cells, harbor mutations in the Wnt- $\beta$-catenin system, resulting in constitutive $\beta$-catenin activation [28]. As such, both $\beta$-catenin and TCF4 siRNA suppressed NRF3 mRNA expression in A172 and H1299 cells but not in HeLa cells. In DLD-1 cells, $\beta$-catenin siRNA but not TCF4 siRNA caused a reduction in NRF3 expression, implying the possibility that $\beta$-catenin activates NRF3 expression through other TCF family members. Supporting these results, these cell lines, but not HeLa cells, showed nuclear $\beta$-catenin accumulation, implying that it was transcriptionally active (Figure 3B and Supplementary Figure S1). Moreover, we addressed the biological relevance of the $\beta$-catenin/TCF4 complex in relation to the NRF3 homologue NRF1 (Figure 3C). The data revealed that $\beta$-catenin or TCF4 knockdown did not affect the expression of NRF1. These data indicate that the $\beta$-catenin/TCF4-NRF3 axis is present in other tissue-derived cancer cells that harbor mutations in the Wnt pathway. 
A

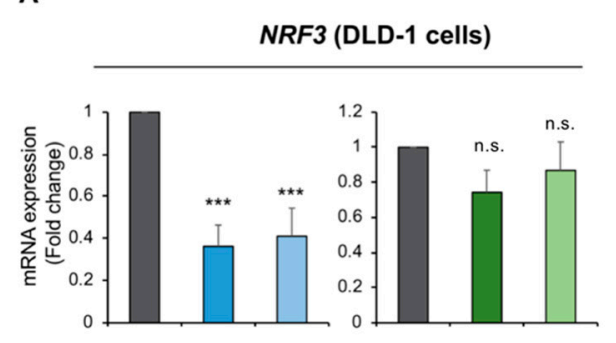

NRF3 (H1299 cells)

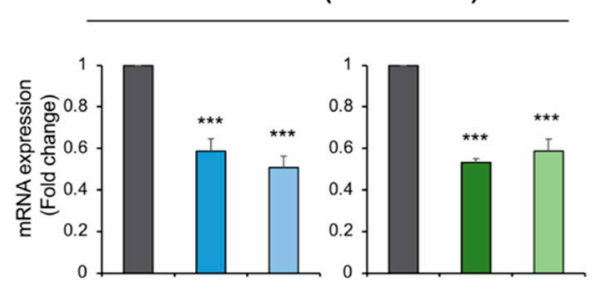

B

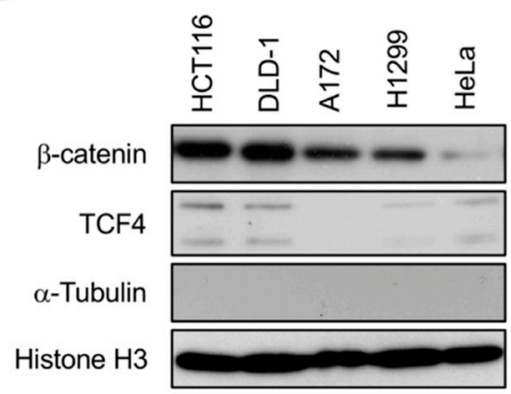

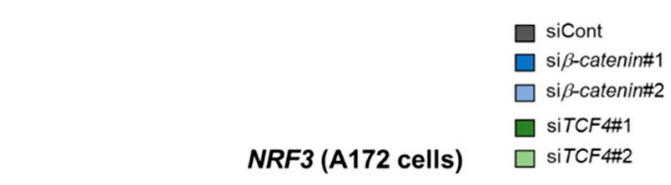

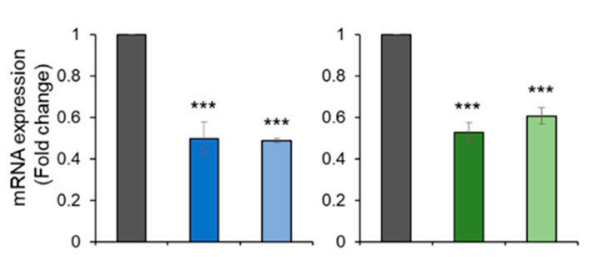

NRF3 (HeLa cells)

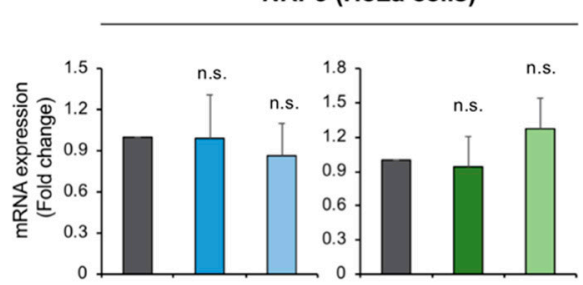

C
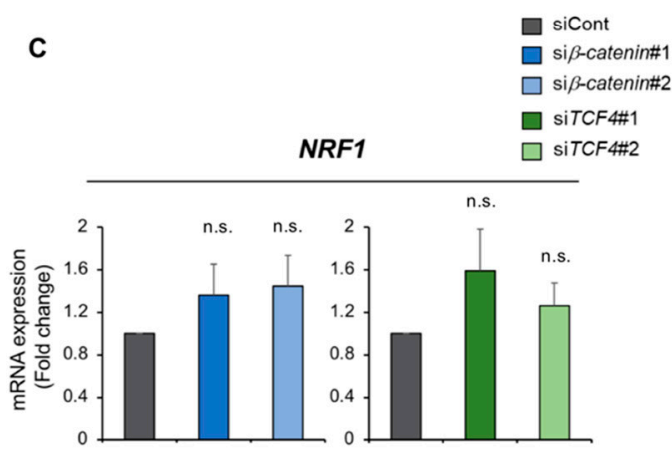

Figure 3. The $\beta$-catenin/TCF4 complex induces NRF3 gene expression in cancer cell lines with mutations in the Wnt- $\beta$-catenin pathway. (A) Knockdown of $\beta$-catenin or TCF4 was performed in DLD-1, A172, H1299 (mutated Wnt- $\beta$-catenin system) and HeLa cells (intact Wnt- $\beta$-catenin system). The experiment was performed as described in the legend for Figure 2. (B) Nuclear localization of $\beta$-catenin and TCF4 in cancer cells. Nuclear extracts from the indicated cells were prepared and subjected to western blot analyses. Histone H3 served as a loading control. The absence of $\alpha$-Tubulin in the extracts indicates no cytoplasmic fraction contamination. (C) qRT-PCR analysis of NRF1 upon $\beta$-catenin or TCF4 knockdown in HCT116 cells. mRNA expression levels were normalized to $\beta$-actin expression, and the data are presented as the mean $\pm \mathrm{SD}(n=3) .{ }^{* * *} p<0.005$, n.s., not significant (ANOVA-Tukey in $(\mathbf{A}, \mathbf{C})$ ).

\subsection{NRF3 Activates Cell Proliferation and GLUT1 Gene Expression in Colon Cancer Cells}

Our finding highlighted another question: what is the biological function of induced NRF3 in cancer cells? We previously revealed that NRF3 knockdown reduced DLD-1 cell growth [11]. Similar experiments using HCT116 cells demonstrated that NRF3 siRNA significantly reduced cell growth (Figure 4A). To identify direct NRF3 target genes in cancer cells, we searched ChIP sequence data for MAFF and MAFK in the ChIP-Atlas database [29] because ChIP sequence data for NRF3 were not available and because these sMaf proteins are heterodimerization partners of NRF3. Intriguingly, we discovered MAFF- and MAFK-ChIP peaks on three species-conserved AREs in the GLUT1 (SLC2A1) gene (Figure 4B). Because GLUT1 is well known to uptake glucose for the proliferation of glycolytic cancer cells [24,25], it is possible that NRF3 promotes cell proliferation by mediating GLUT1 expression. To validate this possibility, we first performed ChIP analysis to determine the recruitment of NRF3 to these ARE sites (Figure 4C). The results clearly demonstrated that NRF3 binds to these ARE sites in 
the GLUT1 gene enhancer. We next conducted siRNA knockdown experiments (Figure 4D). NRF3 siRNA clearly reduced GLUT1 expression at both the mRNA and protein levels. We had found that NRF3 promotes the degradation of the tumor suppressor p53 through activating the 20S proteasome [manuscript submitted by Waku et al.]. In addition, p53 is reported to downregulate GLUT1 gene expression [30]. To examine the possibility that NRF3 activates GLUT1 expression by downregulating p53, we conducted a double knockdown experiment and found negative results (Supplementary Figure S3). We thus conclude that NRF3 leads to the upregulation of the GLUT1 gene in cancer cells.

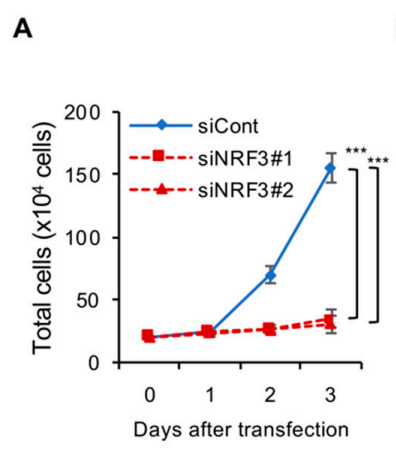

C

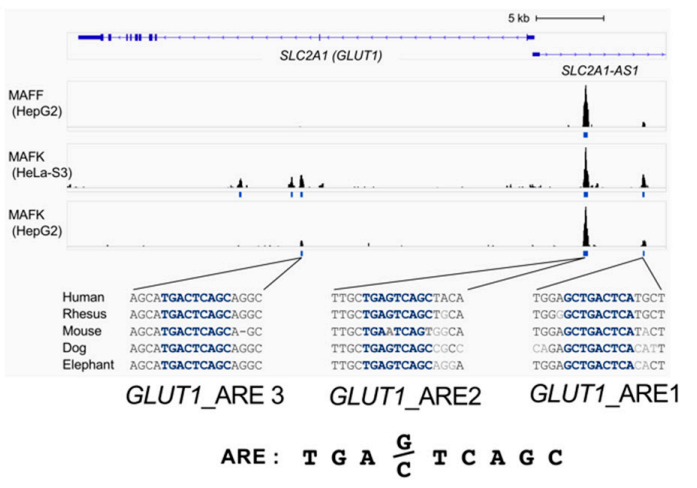

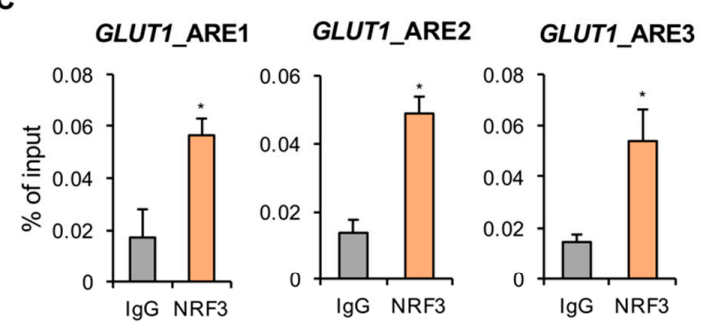

D

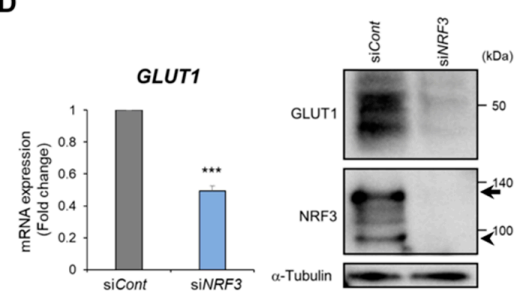

Figure 4. NRF3 activates cell proliferation and GLUT1 gene expression in cancer cells. (A) NRF3 knockdown significantly reduced the proliferation of HCT116 cells. The cells were transfected with control siRNA or NRF3 siRNA\#1 or \#2. At 1-3 days after transfection, the cell numbers were counted using a hemocytometer. The initial cell numbers at the time of transfection were $1 \times 10^{5}$. The data are presented as the mean $\pm \mathrm{SD}(n=3)$. ${ }^{* * *} p<0.005$ (ANOVA/Tukey). (B) Three species-conserved ARE sites (NRF3 recognition sequence) were present in the promoter region and the second intron of the GLUT1 (SLC2A1) gene. ChIP-seq data (SRX150386, SRX150370, SRX150689) in the ChIP-Atlas database show the binding of MAFF and MAFK as heterodimer partners of NRF3 to the AREs in the GLUT1 gene. The blue bars represent the peak regions. The ARE sequences in the human gene are highly conserved among several species (blue). (C) ChIP analysis using HCT116 cells revealed NRF3 binding to three ARE sequences in the GLUT1 gene. ${ }^{*} p<0.05$ ( $t$-test). (D) NRF3 knockdown attenuated GLUT1 gene expression at both the mRNA and protein levels. NRF3 siRNA was transfected into HCT116 cells, and GLUT1 gene expression was determined by qRT-PCR at $48 \mathrm{~h}$ after transfection. The arrows and arrowheads in the immunoblot indicate the cytoplasmic and nuclear forms of NRF3, respectively. RNA expression levels were normalized to $\beta$-actin expression, and data are presented as the mean \pm SD $(n=3) .{ }^{* * *} p<0.005$ (t-test). 


\subsection{The $\beta$-catenin/Tcf4-Nrf3 Axis Is Conserved in Mouse Intestinal Tumors}

To further validate our finding regarding the $\beta$-catenin/TCF4-NRF3 axis, we performed in vivo experiments using mouse intestine. Apc $\Delta 716$ mice develop intestinal tumors due to a null mutation in the $A p c$ gene, thereby activating $\beta$-catenin [31]. Upon analyzing intestinal tumors in $A p c \Delta 716$ mice, we observed significant upregulation of Nrf3 expression and the $\beta$-catenin target gene $c-M y c$ (Figure 5A).

A
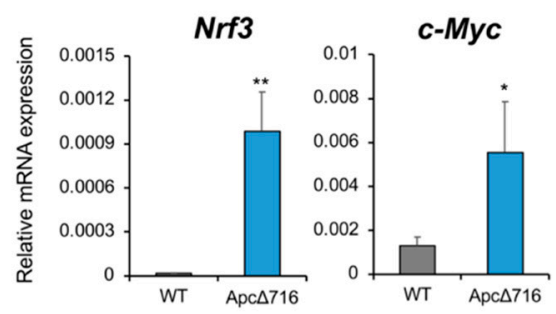

B

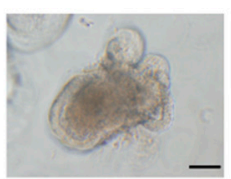

$A p c^{\text {floxfllox }}$

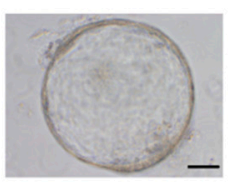

Apc KO

C
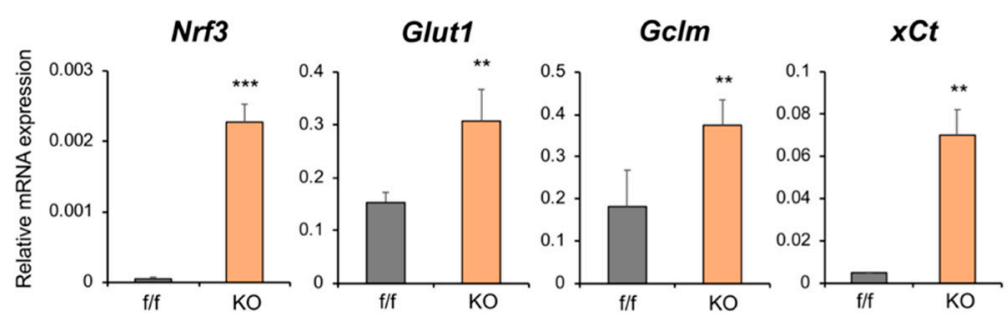

$c-M y c$

$\operatorname{Axin2}$

Lgr5

Cd44

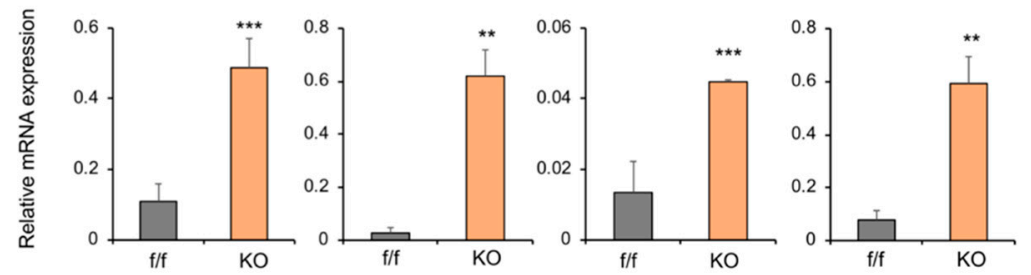

D
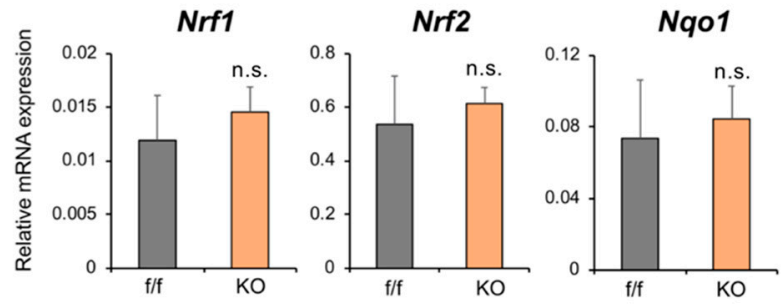

Figure 5. Apc gene deletion induces $N r f 3$ gene expression in mouse intestine and organoids. (A) Nrf3 expression, along with that of the $\beta$-catenin target gene $c-M y c$, was remarkably higher in intestinal tumors from $A p c \Delta 716$ mice than in those from wild-type mice $(n=4)$. (B) Appearance of intestinal epithelial organoids derived from $A p c^{\text {flox/flox }}$ and $A p c$ KO mice. Scale bar, $20 \mu \mathrm{m}$. (C) Loss of the $A p c$ gene in organoids augmented the expression of the Nrf3 and Glut1 genes, along with that of $\beta$-catenin target genes (c-Myc, Axin2, Lgr5), as shown by qRT-PCR analysis. $\mathrm{f} / \mathrm{f}$ and $\mathrm{KO}$ stand for $A p c^{\text {flox/flox }}$ and $A p c \mathrm{KO}$, respectively. The $\operatorname{Lgr} 5$ and $C d 44$ genes are stem/progenitor cell markers of intestinal epithelial cells. Gclm and $x \mathrm{Ct}$ are ARE-containing target genes of CNC family proteins. (D) Gene expression of the Nrf3-related factors Nrf1 and Nrf2 was not altered. Nqo1 is a target gene of Nrf2. The mRNA expression of each gene was normalized to Gapdh expression, and the data are presented as the mean \pm $\operatorname{SD}(n=3) .{ }^{*} p<0.05,{ }^{* *} p<0.01,{ }^{* *} p<0.005$, n.s., not significant $(t$-test).

We next conducted similar experiments using mouse intestine-derived organoids to eliminate nonepithelial cell contamination. Organoids are considered to recapitulate physiological tissues 
better than a conventional two-dimensional (2D) culture system because of their self-organizing structures [32-34]. We generated mouse intestine-derived organoids lacking the Apc gene (KO) by

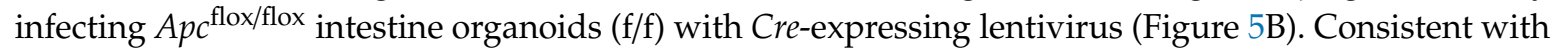
previous reports [35,36], Apc deletion induced the $\beta$-catenin target genes $c-M y c$ and Axin 2 as well as the intestine epithelial stem cell markers Lgr5 and Cd44 (Figure 5C). Importantly, Apc KO organoids showed high induction of the Nrf3 gene. We also observed significant upregulation of the Glut1 gene as well as the Gclm and $x \mathrm{Ct}$ genes, which are known to contain AREs, in Apc KO organoids. Alternatively, loss of Apc did not induce the expression of Nrf1, Nrf2 or its target gene Nqo1 (Figure 5D). Our findings suggest that the $\beta$-catenin/TCF4-NRF3 axis is conserved in mouse intestinal tumors.

\subsection{Correlation of Gene Expression between NRF3 and Target Genes of The $\beta$-catenin/TCF4 Complex in a Human Cancer Database}

Finally, we searched the GEPIA database to confirm the physiological relevance of the association between the Wnt- $\beta$-catenin pathway and NRF3 (Figure 6). Because $c-M Y C$ and LGR5 are direct target genes of the $\beta$-catenin/TCF4 complex, the analysis showed a significant correlation among them. We thus conclude that NRF3 is induced by the $\beta$-catenin/TCF4 complex in human cancer cells.
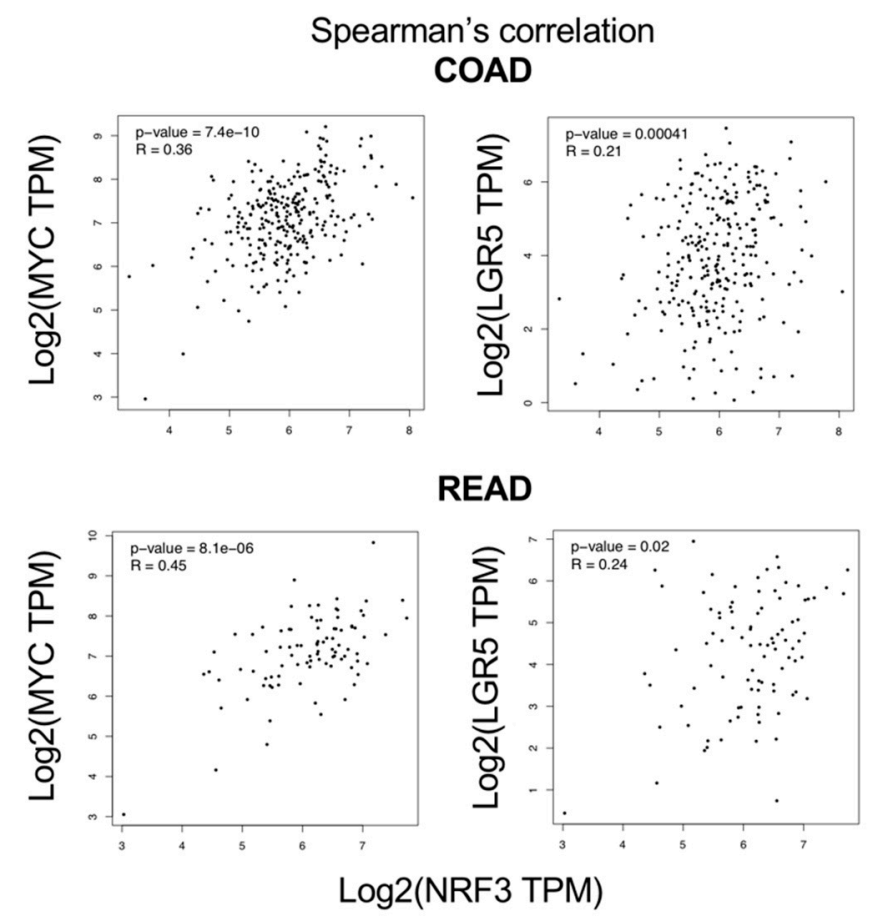

Figure 6. Correlation of NRF3 gene expression and that of the $\beta$-catenin target genes $c-M Y C$ and LGR5 in human colorectal cancer. Spearman's correlation plots represent the colorectal adenocarcinoma (COAD) and rectal adenocarcinoma (READ) results from the GEPIA database.

\section{Discussion}

Our present study identified that the $\beta$-catenin/TCF4 complex in the Wnt signaling pathway activates NRF3 mRNA expression, consequently leading to the upregulation of cell proliferation and GLUT1 gene expression in cancer cells (Figure 7). Tumors evolve by acquiring a series of sequential gene mutations that endow cells with the hallmarks of cancer, including resistance to apoptosis and self-sufficiency in growth signals [17]. The mutations that confer a selective growth advantage to the cell are called "driver" mutations. For instance, mutation of the tumor suppressor APC gene in the $W n t / \beta$-catenin pathway is an initial and crucial event in normal epithelial cells that initiates human sporadic colorectal tumorigenesis [37]. Additionally, it has been reported that $A P C$ mutations cause global metabolic reprogramming of cells by inducing the expression of the protooncogene $c-M Y C$, a 
$\beta$-catenin target gene [21-23]. Based on these results, we surmise that NRF3 plays a physiological role in the initiation of tumorigenesis.
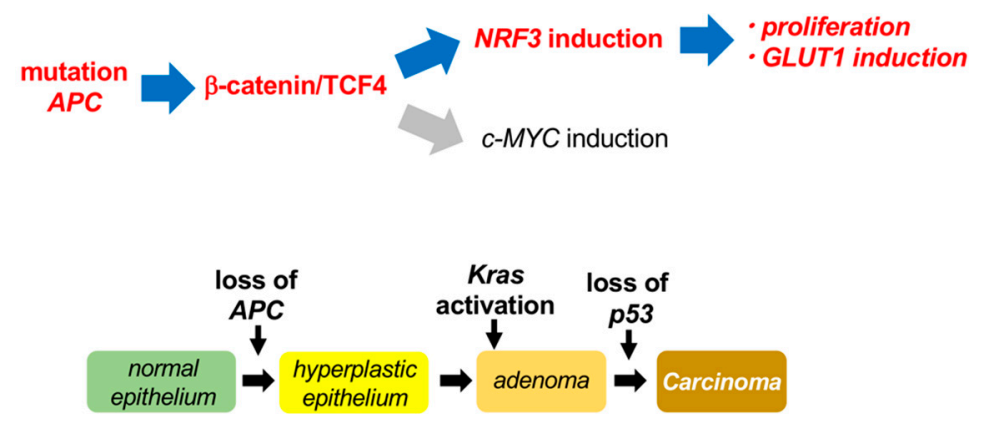

Figure 7. Schematic model of the $\beta$-catenin/TCF4-NRF3 axis in cancer cells. APC gene deletion is a crucial first step in the initiation of human sporadic colorectal cancer [17]. This deletion activates $\beta$-catenin protein and, consequently, the TCF4-mediated expression of tumor-related genes such as the protooncogene $c-M Y C$. This study showed that $\beta$-catenin/TCF4 also activates NRF3 mRNA expression, which leads to the upregulation of proliferation and GLUT1 gene expression in cancer cells. These results define a new biological function of the $\beta$-catenin/TCF4-NRF3 axis in cancer cells.

We recently discovered that NRF3 activates the proliferation of cancer cells by promoting the degradation of the tumor suppressor p53 through activating the $20 \mathrm{~S}$ proteasome [11] (Waku et al., under submission). Inhibition of the tumor suppressor function of p53 is required to acquire resistance to cell death, a crucial cancer hallmark. Nevertheless, it has been reported that $p 53$ gene mutations arise at the final step of colorectal tumor development, eventually generating malignant carcinoma (Figure 7) [17]. Thus, we also consider that one biological function of NRF3 might be the suppression of p53 function before its genetic inhibition at the final stage of cancer onset.

Sustaining the stemness of intestine epithelial stem and progenitor cells is indispensable for the development of colorectal tumors [18]. To this end, the $\beta$-catenin/TCF4 complex augments the expression of stemness-related genes, such as the Axin 2 and Lgr5 genes, thereby promoting the proliferation of stem/progenitor cells. Consistently, we showed that $A p c$ deletion in mouse Apclox/flox organoids substantially induced the expression of these genes along with the Nrf3 gene (Figure 5C). It is also possible that NRF3 plays biological roles in sustaining the stemness of intestine epithelial stem/progenitor cells.

It appears that $\beta$-catenin/TCF4 merely mediates the expression of NRF3 target genes by inducing NRF3 mRNA. However, NRF3 can be considered a stress-inducible transcription factor because of our following three observations: (1) Under physiological conditions, NRF3 is sequestered in the endoplasmic reticulum (ER), thereby preventing its nuclear translocation and transcriptional activity [38]. (2) The ERAD-related E3 ubiquitin ligase HRD1 promotes the cytoplasmic degradation of NRF3 [11]. (3) The nuclear translocation of NRF3 requires the proteolytic enzyme DDI2, through a similar mechanism as that of NRF1 [11] (arrow and arrowheads in Figure 2E,G and Figure 4D). This evidence allows us to hypothesize that certain unidentified stresses and/or signals trigger both cytoplasmic sequestration escape and nuclear entry of NRF3. This hypothetical mechanism may explain in part why Nrf3 knockout mice do not show apparent abnormalities under physiological conditions $[8,9]$. Considering that $A P C$ mutations dramatically change the cell metabolic status by inducing the $c-M Y C$ gene, some metabolites or activated signal transduction pathways may activate the nuclear translocation of NRF3. For a comprehensive understanding of the physiological function of NRF3 in cancer cells, the identification of intrinsic NRF3 activation and/or stress signals remains a crucial issue.

We found that the glucose transporter GLUT1 is a candidate NRF3 target gene in colon cancer cells. This finding is reasonable because cancer cells dramatically change their metabolic status from oxidative phosphorylation to glycolysis by activating $c-M Y C$, a $\beta$-catenin target gene [21]. We need to explore 
whether NRF3-mediated GLUT1 expression confers glucose uptake and proliferation abilities to cancer cells. Unfortunately, we could not show that GLUT1 knockdown reduces glucose uptake by HCT116 cells (data not shown). Because GLUT3 mRNA is also induced in an NRF3-independent mechanism in cancer cells [24,25], GLUT3 might compensate for the loss of GLUT1 function. Further examination is required to determine the effects of NRF3-mediated GLUT1 gene expression on cancer cells.

\section{Materials and Methods}

\subsection{Reagents and Antibodies}

iCRT14 was purchased from Sigma-Aldrich (SML0203) (St. Louis, MO, USA). The antibodies utilized were anti- $\beta$-catenin (610153; BD Biosciences, San Jose, CA, USA), anti-TCF4 (C48H11; Cell Signaling Technology, Danvers, MA, USA), anti- $\alpha$-Tubulin (DM1A; Sigma-Aldrich, St. Louis, MO, USA), and anti-histone H3 (06-755; Millipore, Billerica, MA, USA). Normal mouse IgG (Santa Cruz Biotechnology, Dallas, TX, USA) and normal rabbit IgG (Wako Pure Chemicals, Osaka, Japan) were used for chromatin immunoprecipitation analysis. A monoclonal NRF3 antibody (\#9408) raised against human NRF3 (amino acids 364-415) was generated as described previously [11].

\subsection{RNA Dot Blot Analysis}

The Human Multiple Tissue Expression (MTE ${ }^{\mathrm{TM}}$ ) Array, which contains dots of polyA ${ }^{+}$RNA normalized to ubiquitin from 76 different human tissues, was purchased from Clontech (7775-1; Lot \#8110216, Palo Alto, CA, USA). A radiolabeled probe was prepared from the 500-bp HindIII fragment of the human clone SKhNrf3/1-1 [4]. Hybridization was performed according to the manufacturer's instructions.

\subsection{Cell Culture}

HCT116, DLD-1, A172, and HeLa cells were cultured in DMEM (Wako Pure Chemicals, Osaka, Japan) supplemented with 10\% FBS (Sigma-Aldrich, St. Louis, MO, USA) and 1\% penicillin/streptomycin (Wako Pure Chemicals, Osaka, Japan). H1299 cells were cultured in RPMI1640 (Nacalai Tesque, Kyoto, Japan) supplemented with 10\% FBS and 1\% penicillin/streptomycin. L-WRN cells (CRL-3276; ATCC) were cultured in DMEM (Wako Pure Chemicals, Osaka, Japan) supplemented with $10 \%$ FBS. All cell lines were cultured in a humidified incubator at $5 \% \mathrm{CO}_{2}$ and $37^{\circ} \mathrm{C}$.

\subsection{Apc floxflox and Apc $\Delta 716$ Mice}

$A p c^{\text {floxfflox }}\left(A p c^{580 S}\right.$ flox/580S flox $)$ mice were kind gifts from Ryoji Yao [35]. Generation of Apc $\Delta 716$ mice was described previously [31]. All animals were housed under specific pathogen-free conditions according to the regulations of the standards for human care and use of laboratory animals of Doshisha University (A18020) and the Chiba Cancer Center Research Institute (18-6, 11 April 2018) and the guidelines for the proper conduct of animal experiments of the Ministry of Education, Culture, Sports, Science and Technology of Japan (http://www.mext.go.jp/b_menu/hakusho/nc/06060904.htm).

\subsection{Preparation of, Culture of and Apc Gene Deletion in Intestine Organoids Derived from Apc ${ }^{\text {floxflox }}$ Mice}

Mouse intestine-derived organoids were generated from $A p c^{\text {flox/flox }}$ mice as described previously [36]. Apc-deficient organoids $(A p c \mathrm{KO})$ were generated by infecting $A p c^{\text {flox/flox }}$ organoids with Cre-expressing lentivirus from the LV-Cre pLKO.1 plasmid encoding Cre-recombinase (25997; Addgene). Organoids were seeded on Matrigel (354234; Corning; Corning, NY, USA). Apclox/flox organoids were cultured in Advanced DMEM/F12 (12634; Life Technologies, Carlsbad, CA, USA) supplemented with L-WRN cell conditioned medium, 1\% penicillin/streptomycin (Wako Pure Chemicals, Osaka, Japan), EGF (315-09; Peprotech, Inc. Rocky Hill, NJ, USA) and Y-27632 (a Rock inhibitor) (253-00513; Wako Pure Chemicals, Osaka, Japan). L-WRN cell conditioned medium was prepared as described in [39]. Apc KO organoids were cultured in Advanced DMEM/F12 supplemented with 1\% penicillin/streptomycin, 
EGF, Y-27632 and L-glutamine (Thermo Fisher Scientific Inc. Rockford, IL, USA) in a humidified incubator at $5 \% \mathrm{CO}_{2}$ and $37^{\circ} \mathrm{C}$.

\subsection{Transfection}

The transfection of short interfering RNA (siRNA) was performed using RNAiMAX (Thermo Fisher Scientific Inc. Rockford, IL, USA) according to the manufacturer's protocols. Sequences of siRNAs targeting human mRNAs are listed in Table S1.

\subsection{RNA Extraction and Quantitative Real-Time PCR ( $q R T-P C R)$}

Total RNA was prepared using ISOGENII (Nippon Gene, Tokyo, Japan). One microgram of total RNA was utilized for cDNA synthesis using random hexamer primers (Takara Bio, Ohtsu, Japan) and Moloney murine leukemia virus (M-MLV) reverse transcriptase (Thermo Fisher Scientific Inc. Rockford, IL, USA). qRT-PCR was conducted using SYBR Premix Ex Taq II (Takara Bio, Ohtsu, Japan) and a Thermal Cycler Dice Real Time System II (Takara Bio, Ohtsu, Japan). The PCR conditions were $95^{\circ} \mathrm{C}$ for $30 \mathrm{sec}, 30 \mathrm{cycles}$ of $95^{\circ} \mathrm{C}$ for $5 \mathrm{sec}, 60^{\circ} \mathrm{C}$ for $30 \mathrm{sec}$ and $95^{\circ} \mathrm{C}$ for $15 \mathrm{sec}, 60^{\circ} \mathrm{C}$ for $30 \mathrm{sec}$ and 95 ${ }^{\circ} \mathrm{C}$ for $15 \mathrm{sec}$. All target gene expression levels were normalized to $\beta$-actin or Gapdh expression. The sequences of the primers used are listed in Table S2.

\subsection{Cell Fractionation and Western Blot Analysis}

To prepare whole cell extracts, cells were lysed with SDS sample buffer (50 mM Tris- $\mathrm{HCl}$ ( $\mathrm{pH}$ 6.8), $10 \%$ glycerol and $1 \% \mathrm{SDS}$ ). For nuclear extracts, cells were lysed in buffer A (10 mM Tris- $\mathrm{HCl}(\mathrm{pH} 8.0)$, $10 \mathrm{mM} \mathrm{KCl}, 0.1 \mathrm{mM}$ EDTA, $1.5 \mathrm{mM} \mathrm{MgCl}_{2}$ ), 1x protease inhibitor (Nacalai Tesque, Kyoto, Japan), $10 \mu \mathrm{M}$ MG132 (Peptide Institute, Osaka, Japan) and 10\% NP-40 (final concentration 2\%). After centrifugation, the precipitated nuclei were lysed with SDS sample buffer. The protein concentrations of the cell extracts were measured using a bicinchoninic acid (BCA) kit (Thermo Fisher Scientific Inc. Rockford, IL, USA). Proteins were separated by sodium dodecyl sulfate-polyacrylamide gel electrophoresis (SDS-PAGE) and transferred to PVDF membranes (Immobilon-P transfer membrane, Millipore, Billerica, MA, USA). The blots were incubated with the primary antibodies indicated on the figures and then with a horseradish peroxidase-conjugated secondary antibody (Thermo Fisher Scientific Inc. Rockford, IL, USA). The protein bands were visualized using enhanced chemiluminescence (GE Healthcare, Pittsburgh, PA, USA).

\subsection{Chromatin Immunoprecipitation (ChIP)}

HCT116 cells grown on a 10-cm dish were cross-linked in 1\% formaldehyde for $10 \mathrm{~min}$, followed by quenching with $0.125 \mathrm{M}$ glycine for $5 \mathrm{~min}$ at room temperature and two washes with ice-cold phosphate-buffered saline (PBS). ChIP analysis was conducted as described previously [40], with minor modifications as follows: immunoprecipitated DNA was purified by phenol-chloroform extraction and ethanol precipitation, dissolved in TE and analyzed by quantitative real-time PCR. The utilized antibodies were anti-NRF3 (\#9408), anti- $\beta$-catenin (610153; BD Biosciences, San Jose, CA, USA) and anti-TCF4 (C48H11; Cell Signaling Technology, Danvers, MA, USA). Melting curves of qRT-PCR show the specificity of the reaction (Supplementary Figure S2). The sequences of the primers used are listed in Table S2.

\subsection{Cell Proliferation Assay}

HCT116 cells were plated onto 6-well dishes $\left(1 \times 10^{5}\right.$ cells per well), transfected with the indicated siRNA and cultured for the indicated number of days. The cells were detached from plates with $0.05 \%$ trypsin and gently suspended in ice-cold PBS. Cell counting was performed using a hemocytometer. 


\subsection{Statistical Analysis}

The statistical significance of repeated measurements was evaluated using ANOVA-Tukey's t-test and Student's $t$-test. All values are presented as the mean \pm standard deviation (SD) of at least three independent experiments.

Supplementary Materials: Supplementary materials can be found at http://www.mdpi.com/1422-0067/20/13/ $3344 / s 1$.

Author Contributions: All authors reviewed the manuscript. S.A. performed most of the experiments, analyzed the data and wrote the drafts of the manuscript. A.H. (Ayari Hatanaka) performed the siRNA knockdown experiments. A.H. (Atsushi Hatanaka) performed and analyzed the ChIP experiment in Figure 4B,C. Y.G. performed the $A p c \Delta 716$ mouse experiments in Figure 5A. Y.H. generated the $A p c^{f l o x f f l o x}$ mouse intestine organoids. M.M.T. provided the $A p c \Delta 716$ mice. T.W. performed the cell proliferation assay in Figure $4 \mathrm{~A}$ and acquired the funding. A.K. designed the research, performed the RNA dot blot analysis in Figure 1 and the organoid experiments in Figure 5B-D, wrote the manuscript and acquired the funding.

Funding: This work was supported in part by grants-in-aid (16H03265 (AK), 17K18234 (TW)) from the Ministry of Education, Culture, Sports, Science and Technology and the Uehara Memorial Foundation (TW).

Acknowledgments: We are grateful to Ryoji Yao, Masahiro Aoki and Elaine Fuchs for the Apc floxfllox (Apc ${ }^{580 S}$ flox/580S flox ) mice, the Apc $\Delta 716$ mice and the LV-Cre pLKO.1 vector, respectively. We also thank Kaoru Orihashi for providing the organoid culture technique.

Conflicts of Interest: The authors declare that they have no conflicts of interest.

\section{Abbreviations}

$\begin{array}{ll}\text { APC } & \text { Adenomatous polyposis coli } \\ \text { ARE } & \text { Antioxidant response element } \\ \text { ChIP } & \text { Chromatin immunoprecipitation } \\ \text { CNC } & \text { Cap "N" collar } \\ \text { LEF } & \text { Lymphoid enhancer-binding factor } \\ \text { NFE2L3 } & \text { NFE2-like 3 } \\ \text { NRF3 } & \text { NFE2-related factor 3 } \\ \text { TCF4 } & \text { T-cell factor 4 } \\ \text { WRE } & \text { Wnt response element }\end{array}$

\section{References}

1. Kandoth, C.; McLellan, M.D.; Vandin, F.; Ye, K.; Niu, B.; Lu, C.; Xie, M.; Zhang, Q.; McMichael, J.F.; Wyczalkowski, M.A.; et al. Mutational landscape and significance across 12 major cancer types. Nature 2013, 502, 333-339. [CrossRef] [PubMed]

2. Willett, C.G.; Chang, D.T.; Czito, B.G.; Meyer, J.; Wo, J. The Cancer Genome Atlas Network Comprehensive molecular characterization of human colon and rectal cancer. Nature 2012, 487, 330-337.

3. Broad Institute TCGA Genome Data Analysis Center. Available online: http://firebrowse.org/viewGene. html?gene=NFE2L3.TCGAdataversion2016_01_28 (accessed on 30 October 2018).

4. Kobayashi, A.; Ito, E.; Toki, T.; Kogame, K.; Takahashi, S.; Igarashi, K.; Hayashi, N.; Yamamoto, M. Molecular Cloning and Functional Characterization of a New Cap'n'Collar Family Transcription Factor Nrf3. J. Biol. Chem. 1999, 274, 6443-6452. [CrossRef] [PubMed]

5. Bugno, M.; Daniel, M.; Chepelev, N.L.; Willmore, W.G. Changing gears in Nrf1 research, from mechanisms of regulation to its role in disease and prevention. Biochim. Biophys. Acta 2015, 1849, 1260-1276. [CrossRef] [PubMed]

6. Yamamoto, X.M.; Kensler, T.W.; Motohashi, H. The Keap1-Nrf2 System: A Thiol-Based Sensor-Effector Apparatus for Maintaining Redox Homeostasis. Physiol. Rev. 2018, 98, 1169-1203. [CrossRef] [PubMed]

7. Chevillard, G.; Blank, V. NFE2L3 (NRF3): The Cinderella of the Cap'n'Collar transcription factors. Cell. Mol. Life Sci. 2011, 3, 3337-3348. [CrossRef] [PubMed]

8. Kobayashi, A.; Ohta, T.; Yamamoto, M.; Ohta, M.; Yamamoto, M. Unique function of the Nrf2-Keap1 pathway in the inducible expression of antioxidant and detoxifying enzymes. Methods Enzymol. 2004, 378, 273-286. 
9. Derjuga, A.; Gourley, T.S.; Holm, T.M.; Heng, H.H.Q.; Shivdasani, R.A.; Ahmed, R.; Andrews, N.C.; Blank, V. Complexity of CNC Transcription Factors As Revealed by Gene Targeting of the Nrf3 Locus. Mol. Cell. Biol. 2004, 24, 3286-3294. [CrossRef]

10. Chevillard, G.; Paquet, M.; Blank, V. Nfe213 (Nrf3) deficiency predisposes mice to T-cell lymphoblastic lymphoma. Blood 2011, 117, 2005-2008. [CrossRef]

11. Chowdhury, A.M.M.A.; Katoh, H.; Hatanaka, A.; Iwanari, H.; Nakamura, N.; Hamakubo, T.; Natsume, T.; Waku, T.; Kobayashi, A. Multiple regulatory mechanisms of the biological function of NRF3 (NFE2L3) control cancer cell proliferation. Sci. Rep. 2017, 7, 12494. [CrossRef]

12. Wang, C.; Saji, M.; Justiniano, S.E.; Yusof, A.M.; Zhang, X.; Yu, L.; Fernández, S.; Wakely, P., Jr.; La Perle, K.; Nakanishi, H.; et al. RCAN1-4 is a thyroid cancer growth and metastasis suppressor. J. Clin. Investig. Insight 2017, 2, e90651. [CrossRef] [PubMed]

13. Wang, H.; Zhan, M.; Yang, R.; Shi, Y.; Liu, Q.; Wang, J. Elevated expression of NFE2L3 predicts the poor prognosis of pancreatic cancer patients. Cell Cycle 2018, 17, 2164-2174. [CrossRef] [PubMed]

14. Chiu, S.T.; Hsieh, F.J.; Chen, S.W.; Chen, C.L.; Shu, H.F.; Li, H. Clinicopathologic correlation of up-regulated genes identified using cDNA microarray and real-time reverse transcription-PCR in human colorectal cancer. Cancer Epidemiol. Biomark. Prev. 2005, 14, 437-443. [CrossRef]

15. Almstrup, K.; Ottesen, A.M.; Sonne, S.B.; Hoei-Hansen, C.E.; Leffers, H.; Rajpert-De Meyts, E.; Skakkebaek, N.E. Genomic and gene expression signature of the pre-invasive testicular carcinoma in situ. Cell Tissue Res. 2005, 322, 159-165. [CrossRef] [PubMed]

16. Rhee, D.K.; Park, S.H.; Jang, Y.K. Molecular signatures associated with transformation and progression to breast cancer in the isogenic MCF10 model. Genomics 2008, 92, 419-428. [CrossRef]

17. Vogelstein, B.; Papadopoulos, N.; Velculescu, V.E.; Zhou, S.; Diaz, L.A.; Kinzler, K.W. Cancer genome landscapes. Science 2013, 339, 1546-1558. [CrossRef] [PubMed]

18. Nusse, R.; Clevers, H. Wnt/ $\beta$-Catenin Signaling, Disease, and Emerging Therapeutic Modalities. Cell 2017, 169, 985-999. [CrossRef]

19. Cadigan, K.M.; Waterman, M.L. TCF/LEFs and Wnt Signaling in the Nucleus. Cold Spring Harb. Perspect. Biol. 2012, 4, a007906. [CrossRef]

20. Fearon, E.R. Molecular genetics of colorectal cancer. Annu. Rev. Pathol. 2011, 6, 479-507. [CrossRef]

21. Satoh, K.; Yachida, S.; Sugimoto, M.; Oshima, M.; Nakagawa, T.; Akamoto, S.; Tabata, S.; Saitoh, K.; Kato, K.; Sato, S.; et al. Global metabolic reprogramming of colorectal cancer occurs at adenoma stage and is induced by MYC. Proc. Natl. Acad. Sci. USA 2017, 114, E7697-E7706. [CrossRef]

22. Yochum, G.S.; Cleland, R.; Goodman, R.H. A Genome-Wide Screen for $\beta$-Catenin Binding Sites Identifies a Downstream Enhancer Element That Controls c-Myc Gene Expression. Mol. Cell. Biol. 2008, 28, 7368-7379. [CrossRef] [PubMed]

23. Bottomly, D.; Kyler, S.L.; McWeeney, S.K.; Yochum, G.S. Identification of $\beta$-catenin binding regions in colon cancer cells using ChIP-Seq. Nucleic Acids Res. 2010, 38, 5735-5745. [CrossRef] [PubMed]

24. Labak, C.M.; Wang, P.Y.; Arora, R.; Guda, M.R.; Asuthkar, S.; Tsung, A.J.; Velpula, K.K. Glucose transport: Meeting the metabolic demands of cancer, and applications in glioblastoma treatment. Am. J. Cancer Res. 2016, 6, 1599-1608. [PubMed]

25. Ancey, P.-B.; Contat, C.; Meylan, E. Glucose transporters in cancer: From tumor cells to the tumor microenvironment. FEBS J. 2018, 285, 2926-2943. [CrossRef] [PubMed]

26. De La Roche, M.; Ibrahim, A.E.K.; Mieszczanek, J.; Bienz, M. LEF1 and B9L shield $\beta$-catenin from inactivation by axin, desensitizing colorectal cancer cells to tankyrase inhibitors. Cancer Res. 2014, 74, 1495-1505. [CrossRef] [PubMed]

27. Gonsalves, F.C.; Klein, K.; Carson, B.B.; Katz, S.; Ekas, L.A.; Evans, S. An RNAi-based chemical genetic screen identifies three small-molecule inhibitors of the Wnt/wingless signaling pathway. Proc. Natl. Acad. Sci. USA 2011, 108, 5954-5963. [CrossRef] [PubMed]

28. Li, V.S.W.; Ng, S.S.; Boersema, P.J.; Low, T.Y.; Karthaus, W.R.; Gerlach, J.P.; Mohammed, S.; Heck, A.J.R.; Maurice, M.M.; Mahmoudi, T.; et al. Wnt Signaling through Inhibition of $\beta$-Catenin Degradation in an Intact Axin1 Complex. Cell 2012, 149, 1245-1256. [CrossRef]

29. Oki, S.; Ohta, T.; Shioi, G.; Hatanaka, H.; Ogasawara, O.; Okuda, Y.; Kawaji, H.; Nakaki, R.; Sese, J.; Meno, C. ChIP-Atlas: A data-mining suite powered by full integration of public ChIP-seq data. EMBO Rep. 2018, 19, e46255. [CrossRef] 
30. Schwartzenberg-Bar-Yoseph, F.; Armoni, M.; Karnieli, E. The Tumor Suppressor p53 Down-Regulates Glucose Transporters GLUT1 and GLUT4 Gene Expression. Cancer Res. 2004, 64, 2627-2633. [CrossRef]

31. Oshima, M.; Oshima, H.; Kitagawa, K.; Kobayashi, M.; Itakura, C.; Taketo, M. Loss of Apc heterozygosity and abnormal tissue building in nascent intestinal polyps in mice carrying a truncated Apc gene. Proc. Natl. Acad. Sci. USA 1995, 92, 4482-4486. [CrossRef]

32. Dutta, D.; Heo, I.; Clevers, H. Disease Modeling in Stem Cell-Derived 3D Organoid Systems. Trends Mol. Med. 2017, 23, 393-410. [CrossRef] [PubMed]

33. Kretzschmar, K.; Clevers, H. Organoids: Modeling Development and the Stem Cell Niche in a Dish. Dev. Cell 2016, 38, 590-600. [CrossRef] [PubMed]

34. Maru, Y.; Onuma, K.; Ochiai, M.; Imai, T.; Hippo, Y. Shortcuts to intestinal carcinogenesis by genetic engineering in organoids. Cancer Sci. 2019, 110, 858-866. [CrossRef] [PubMed]

35. Shibata, H.; Toyama, K.; Shioya, H.; Ito, M.; Hirota, M.; Hasegawa, S.; Matsumoto, H.; Takano, H.; Akiyama, T.; Toyoshima, K.; et al. Rapid Colorectal Adenoma Formation Initiated by Conditional Targeting of the Apc Gene. Science 1997, 278, 120-123. [CrossRef] [PubMed]

36. Onuma, K.; Ochiai, M.; Orihashi, K.; Takahashi, M.; Imai, T.; Nakagama, H.; Hippo, Y. Genetic reconstitution of tumorigenesis in primary intestinal cells. Proc. Natl. Acad. Sci. USA 2013, 110, 11127-11132. [CrossRef] [PubMed]

37. Kinzler, K.; Vogelstein, B. Lessons from Hereditary Review Colorectal Cancer. Cell 1996, 87, $159-170$. [CrossRef]

38. Zhang, Y.; Kobayashi, A.; Yamamoto, M.; Hayes, J.D. The Nrf3 transcription factor is a membrane-bound glycoprotein targeted to the endoplasmic reticulum through its N-terminal homology box 1 sequence. J. Biol. Chem. 2009, 284, 3195-3210. [CrossRef] [PubMed]

39. Miyoshi, H.; Stappenbeck, T.S. In vitro expansion and genetic modification of gastrointestinal stem cells in spheroid culture. Nat. Protoc. 2013, 8, 2471-2482. [CrossRef]

40. Tsuchiya, Y.; Taniguchi, H.; Ito, Y.; Morita, T.; Karim, M.R.; Ohtake, N.; Fukagai, K.; Ito, T.; Okamuro, S.; Iemura, S.; et al. The CK2-Nrf1 axis controls the clearance of ubiquitinated proteins by regulating proteasome gene expression. Mol. Cell. Biol. 2013, 33, 3461-3472. [CrossRef]

(C) 2019 by the authors. Licensee MDPI, Basel, Switzerland. This article is an open access article distributed under the terms and conditions of the Creative Commons Attribution (CC BY) license (http://creativecommons.org/licenses/by/4.0/). 